\title{
Introducing G.RE.T.A. - an innovative geo-resistivimeter for long-term monitoring of earthen dams and unstable slopes
}

\author{
G Tresoldi Politecnico di Milano, Italy
}

A Hojat Shahid Bahonar University of Kerman, Iran and Politecnico di Milano, Italy

L Zanzi Politecnico di Milano, Italy

A Certo LSI Lastem s.r.I., Italy

\begin{abstract}
Nowadays there is an increasing interest in introducing techniques capable of monitoring the internal conditions of embankments and slopes in order to develop early warning alarm systems. Geophysical methods have been widely used in geotechnical risk mitigation studies to evaluate the stability conditions of dams, embankments and slopes. Geophysical methods have the advantage of investigating large volumes of subsurface in a non-invasive manner. Among different geophysical techniques, geo-electrical methods are more frequently used for this purpose.

In previous decades, electrical resistivity tomography (ERT) technique has been widely used in a variety of problems such as engineering investigations, groundwater studies, landfill surveys, mineral exploration, glaciological applications, hydrogeological risk mitigation (e.g. landslides), and monitoring of embankments, earthen dams and tailings dams.

Commercial resistivity instruments are portable devices which are generally capable of investigating the subsurface down to depths of a few hundred metres with high injected currents. These instruments are not customised for long-term installations in remote places. In this paper, we present the design, installation and testing of a new geo-electrical monitoring system customised for long-term monitoring projects.

In the first step, the feasibility of using time-lapse ERT method to study the saturation and de-saturation processes and to monitor anomalous seepage paths in a levee was demonstrated. Then, a long-term geo-electrical monitoring system, G.RE.T.A. (Geo REsistivimeter for Time-lapse Analysis), was designed based on the information obtained in the first step. The G.RE.T.A. system is capable of being programmed remotely and working autonomously

In order to monitor anomalous seepages in levee structures that can lead to the levee breach, two installations of G.RE.T.A. have been completed along two river embankments in northern Italy. In order to develop the system to monitor landslides, laboratory studies are in progress to monitor rainfall-triggered landslides. The results have proved the capability of ERT measurements in delineating inhomogeneous infiltration zones during precipitation and detecting weak zones before collapse.
\end{abstract}

Keywords: ERT method, time-lapse, subsurface monitoring, risk mitigation, long-term installation

\section{Introduction}

Embankments and dams are structures that play an important role in civilisation for a variety of purposes including irrigation, flood protection, hydropower generation, flow regularisation, industrial tailings, urban and industrial water supply, fish farming and tourism. As structures with a crucial importance, they must be reliably monitored. Standard monitoring procedures for dams are based on deformation assessment (using for example inclinometers, extensometers and radars, satellite InSAR, and prisms), and soil saturation measurements using piezometers. Considering river embankments, the situation is even worse: periodic 
visual inspections are often the only monitoring strategy programmed by managing authorities in order to assess the functionality of the structure.

Geophysical methods can help in bridging the gap from external inspections to internal and volumetric measurements of the subsurface. Geophysical measurements respond to soil physical properties, such as composition, granulometry, water content, porosity and density, providing comprehensive data in 2D or 3D from non-destructive campaigns. Geophysical methods have been widely applied to risk mitigation investigations to evaluate the stability conditions of dams, embankments and slopes (Cardarelli et al. 2010; Di Prinzio et al. 2010; Hibert et al. 2012; Morelli \& Francese 2013; Francese \& Monteiro Santos 2014; Busato et al. 2016; Borgatti et al. 2017; Schenato et al. 2017; Crawford \& Bryson 2018; Hojat et al. 2019a). Among different geophysical techniques, electrical resistivity tomography (ERT) method is more suitable in characterising and monitoring the subsurface condition since it can well underline differences in water saturation, soil textures and presence of voids in the subsurface. Resistivity is a parameter that indicates how a specified material resists the electric current flow. Resistivity depends on soil composition, porosity, water content, and the quality of the porewater. Therefore, geo-electrical methods can be effectively used to detect time variations of soil properties. In previous decades, resistivity measurements were widely used in hydro-geophysical investigations, to scan the inner conditions of embankments, dams and landslides (Piegari et al. 2008; Cardarelli et al. 2014; Inazaki et al. 2016; Huntley et al. 2019; Kotikian et al. 2019).

Non-intrusive time-lapse geo-electrical measurements provide a means to image and monitor seepage processes, identify preferential flow paths and quantify soil saturation with time. The possibility of performing time-lapse measurements allows control of the evolution of a phenomenon over time. Nowadays time-lapse geo-electrical measurements are commonly used to investigate the inner structure of soil masses, sometimes also with a permanent installation on the site (Sjödahl et al. 2008; Jomard et al. 2010; Chambers et al. 2014; Perri et al. 2014; Supper et al. 2014; Arosio et al. 2017; Gunn et al. 2018; Tresoldi et al. 2018; Hojat et al. 2019b; Jodry et al. 2019; Tresoldi et al. 2019).

Geo-electrical measurements are not new to the mining sector. They have been widely used to assess acid drainage, contamination plumes and heap leaching (Rucker et al. 2009; Moradipour et al. 2016; Hudson et al. 2018), and to study hydrogeological conditions and to explore the inner structure of tailings dams and piles (Karimi Nasab et al. 2011; Camarero et al. 2019; Dimech et al. 2019; Martín-Crespo et al. 2019).

In this study, a new strategy employing ERT monitoring is proposed in which geo-electrical measurements can be used as real-time monitoring of the inner conditions of the critical parts of earthen levees, landslides, mine wastes, rock piles, heap leaching pads and tailings dams. The system is called G.RE.T.A. (Geo REsistivimeter for Time lapse Analysis) and can be customised for each project to be installed for short-term and long-term monitoring purposes. G.RE.T.A. can work and communicate remotely, providing alarms when user-defined thresholds are passed for hydrogeological risks. It consists of a remotely controlled low-power resistivity-meter with two multi-cables connected to 48 stainless steel $20 \times 20 \mathrm{~cm}$ plate electrodes. The cables are protected by anti-rodent covers in order to be permanently buried in a trench along the study site. The system is accompanied by a weather station to track the meteorological variables such as rainfall, temperature and water level in dam reservoirs/rivers. The monitoring system can be powered by solar panels or by a power grid. The measurement parameters, the frequency of measurements and the data transmission interval can be set depending on the needs of the customer. Datasets including resistivity sections, measurement parameters and the status of the monitoring device are available on a cloud system. Time-lapse data analysis and resistivity comparison tools are available online in order to monitor the subsoil situation in real time. An automatic control algorithm can detect the changing situations and alarm the customer to anomalous changes. 
So far, the system has been installed along two earthen river embankments in Italy to monitor seepage and soil saturation and to prevent levee collapse. It has been also tested at laboratory scale for shallow landslide activation. In January 2020, G.RE.T.A. was installed in the third pilot site, located in Chile. The system is in the demonstration stage now, installed near Santiago, and it is supposed to be permanently moved to a tailings dam in the following months.

\section{Methodology}

The G.RE.T.A. system is a geo-resistivity-meter designed to be installed permanently in the study site, adapted to work remotely for long periods of time. The high quality components are constructed to be resistant to external agents and some parts, such as the cables, are designed to be buried in remote places. The level of International Protection for boxes containing the main instrument and communication components is IP66, while buried cables are IP67. The system is equipped with two 24-channel cables with stainless steel plate electrodes normally spaced from 1 to $3 \mathrm{~m}$. This parameter can be set depending on the desired maximum depth of penetration as well as longitudinal data coverage. If the focus is to cover long distances with shallow measurements (not reaching the maximum depth), electrode spacing can be increased to $8 \mathrm{~m}$ without reaching the limit of current injection. The cables are protected with anti-rodent plastic cases and can be buried horizontally in a trench or deployed vertically in a hole. The system can be powered by a solar panel or by the power grid, according to the available electrical connections at each site. The system can be programmed and works remotely by means of internet connection, sending data with a user-defined frequency. The device communicates with a website where data are stored, visualised and processed, and where the status of the system can be checked and the device can be programmed. After a calibration procedure that may require the collection of a few core samples from the study site, the resistivity maps can be transformed and visualised on the platform as water content maps (or maps of leachate saturation, depending on the project target). The processed data are automatically inverted and analysed to underline changes in the monitored area with time. Thresholds of variations in resistivity or water content can be implemented and alarms can be set when user-defined thresholds are reached.

\subsection{Preliminary measurements}

The preliminary study was focussed on analysing the capability of resistivity measurements in recognising instability problems in earthen embankments. During 2018-2019, numerous measurements were performed with an IRIS-Syscal Pro resistivity-meter in critical levee segments suggested by the managing authorities for river maintenance in northern Italy. The technique could underline different problems related to instability and seepage in embankments: concentrated seepage (Figure 1a), underseepage (Figure 1b), problems of riverbed sealing (Figure 1c), cavities and heterogeneities (Figure 1d). All these measurements were performed to find the cause or to better delineate problems encountered by the authorities, such as water ingresses, subsidence of the top of the levee or collapses. In all cases, water flow paths were identified and the problems were better understood and solved by the authorities.

Time-lapse measurements were also performed to evaluate the potential of quasi-continuous geo-electrical monitoring of different seepage conditions and to recognise in advance critical situations inside the levee structure. Figure 2 illustrates a known concentrated seepage in San Giacomo delle Segnate, which was detected one year earlier than the partial collapse of the embankment. In Figure 2, only three of the six measurements during a year are reported. The low resistivity zone (e.g. blue zone in Figures $2 \mathrm{a}$ and $2 \mathrm{~b}$ ) indicates a piping phenomenon; after the collapse the seepage zone becomes less evident due to the soil compaction (Figure 2c). 


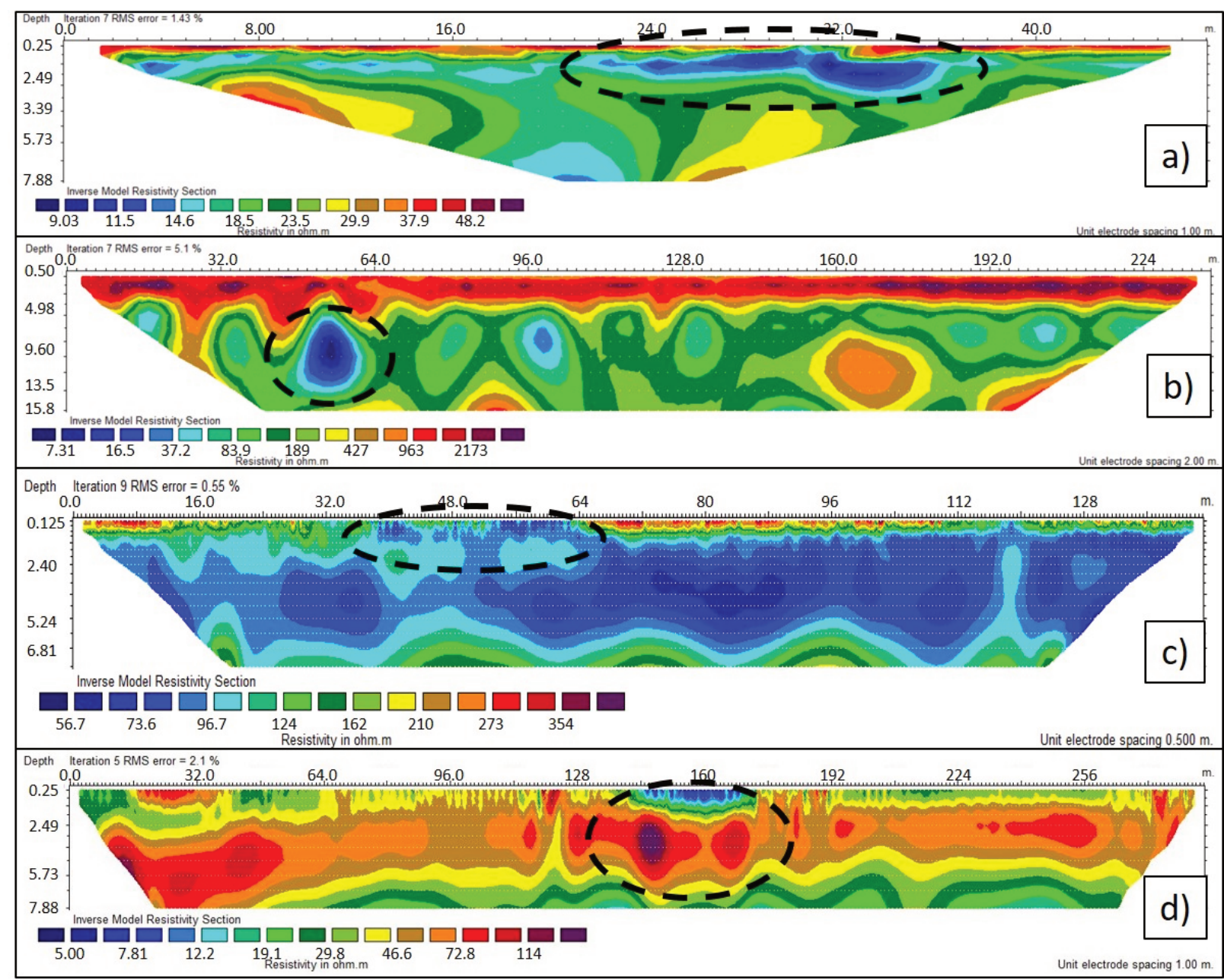

Figure 1 Examples of the inverted resistivity sections from preliminary ERT measurements (the dashed circles show the critical zones): (a) Concentrated seepage in San Giacomo delle Segnate, Dugale site; (b) Underseepage in Castelletto di Cuggiono; (c) Seepage for poor riverbed sealing in Gessate; (d) Heterogeneities below the reconstructed embankment in Colorno

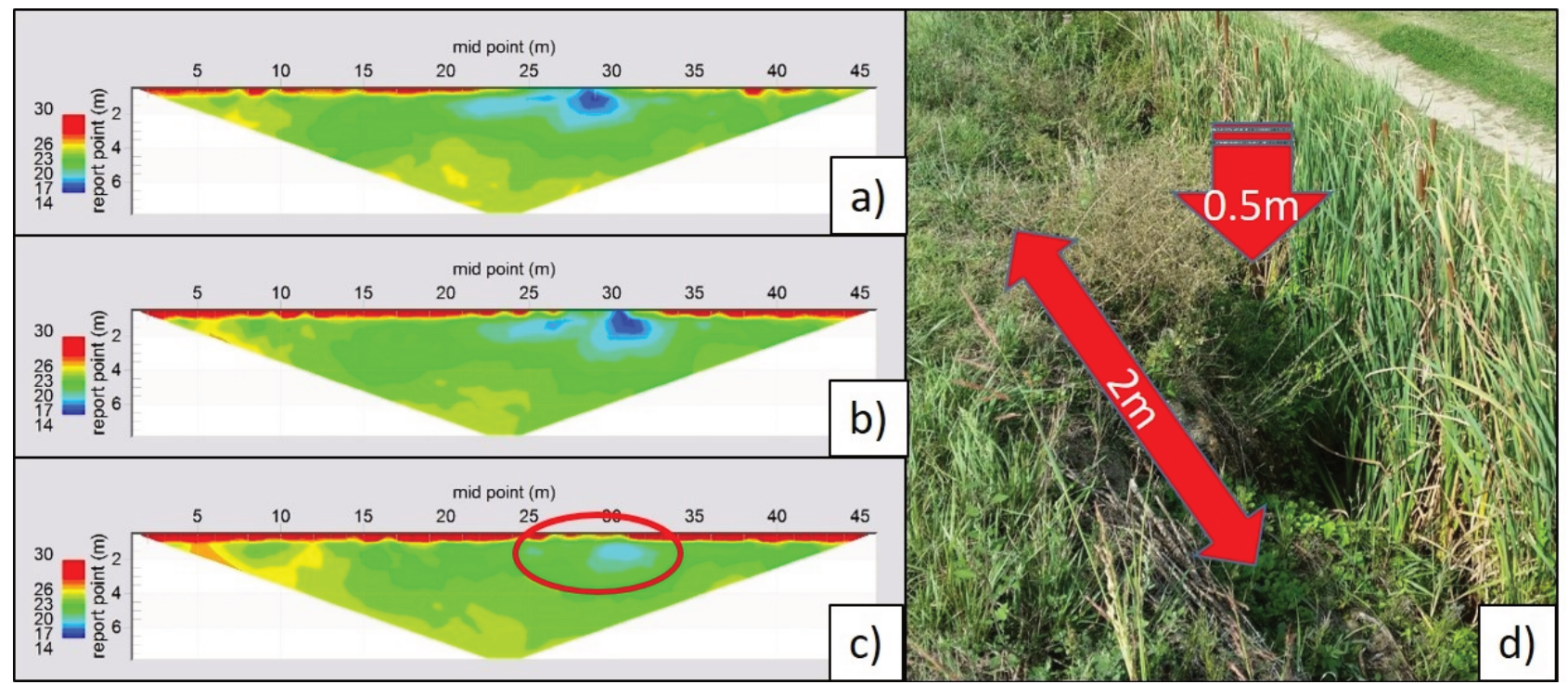

Figure 2 Time-lapse ERT measurements in San Giacomo delle Segnate, Dugale site: (a) First measurement; (b) Measurement after one year; (c) Last measurement after collapse (the red oval identifies the collapsed zone); (d) Partial levee collapse in the site identified by ERT measurements 
The monitoring system was then assembled and installed in selected critical sites. Its measurements were tested through making comparison measurements with commercial devices.

\section{$2.2 \quad$ Installation sites}

Two systems have been customised and installed for hydrogeological risks: one system along an irrigational canal in San Giacomo delle Segnate and the second system along a river levee in Colorno passing over a reconstructed section.

The two sites were selected with the guidance of the managing authorities for river and canals, after preliminary tests that underlined critical issues in the structures. Moreover, the presence of houses, infrastructure, and industrial areas in the surrounding of the levees was carefully considered because they give rise to the level of disaster.

The levee in San Giacomo delle Segnate is in the centre of a village with houses in the surrounding area. It was subjected to previous instabilities and it has a damaged liner coverage on the riverbed. As levees of a controlled canal, the structures in the zone are not very high, with a maximum height of $3 \mathrm{~m}$ from the ground level. The installation was performed in 2015 along the embankment crest, with two 24-channel $1 \mathrm{~m}$ spaced cables deployed in a $0.5 \mathrm{~m}$ deep trench excavated along the central axis of the structure. The Wenner configuration was selected for measurements. The maximum penetration depth for this configuration is $7.5 \mathrm{~m}$ for the survey line which is $47 \mathrm{~m}$ long. The electrodes are plate stainless steel electrodes of $0.2 \times 0.2 \mathrm{~m}$ in dimension. A meteorological station was also installed near the monitoring system. The two devices each have a solar panel and communication systems connected to a website (Figure 3).

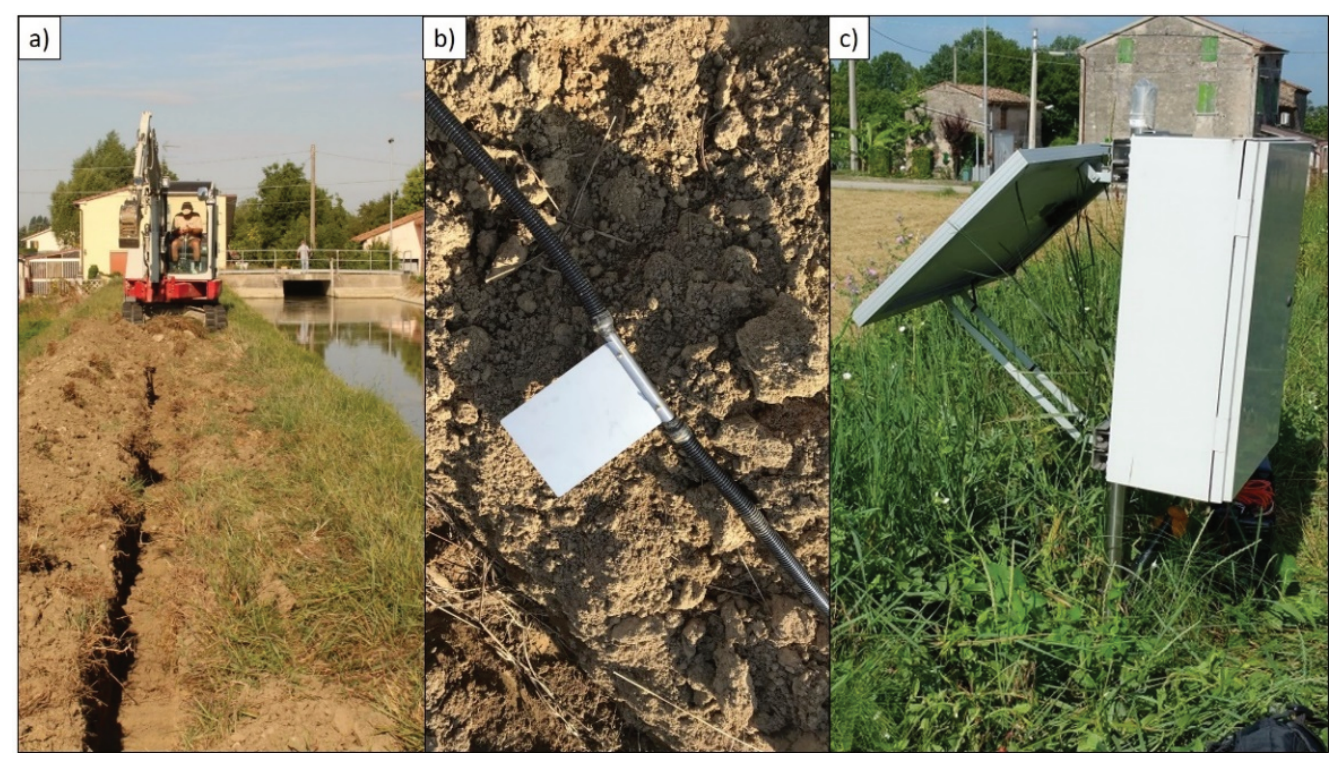

Figure 3 G.RE.T.A. installation in San Giacomo delle Segnate: (a) Trench on the top of the levee; (b) Protected cables and plate electrodes; (c) Geo-resistivimeter box

The city of Colorno was subjected to an extreme flood in 2017 and the Torrent Parma resulted in an overtopping in the centre of the village and two concentrated seepages in the river embankments. The segments were re-built with clayey material to reduce the permeability. Preliminary measurements were undertaken to map the vulnerability of new parts and to discover heterogeneities of pre-existing parts; finally, the re-built site in La Penza (Figure 1d) was selected as the most critical site located in an urbanised zone. The levees of Torrent Parma are $6 \mathrm{~m}$ high and have a wide series of banks because the river is a tributary of Po River and the floods of this river, which is the biggest river in Italy, are often back-propagated into the Parma basin. G.RE.T.A. installation was performed in 2018 along the embankment crest, digging a trench to allocate two 24-channel $2 \mathrm{~m}$ spaced cables attached to plate electrodes. The distance between electrodes was selected to investigate a wider area down to a depth of $15.5 \mathrm{~m}$. In this case, the meteorological station was assembled on the same pole of the resistivimeter, with a common communication system (Figure 4). 


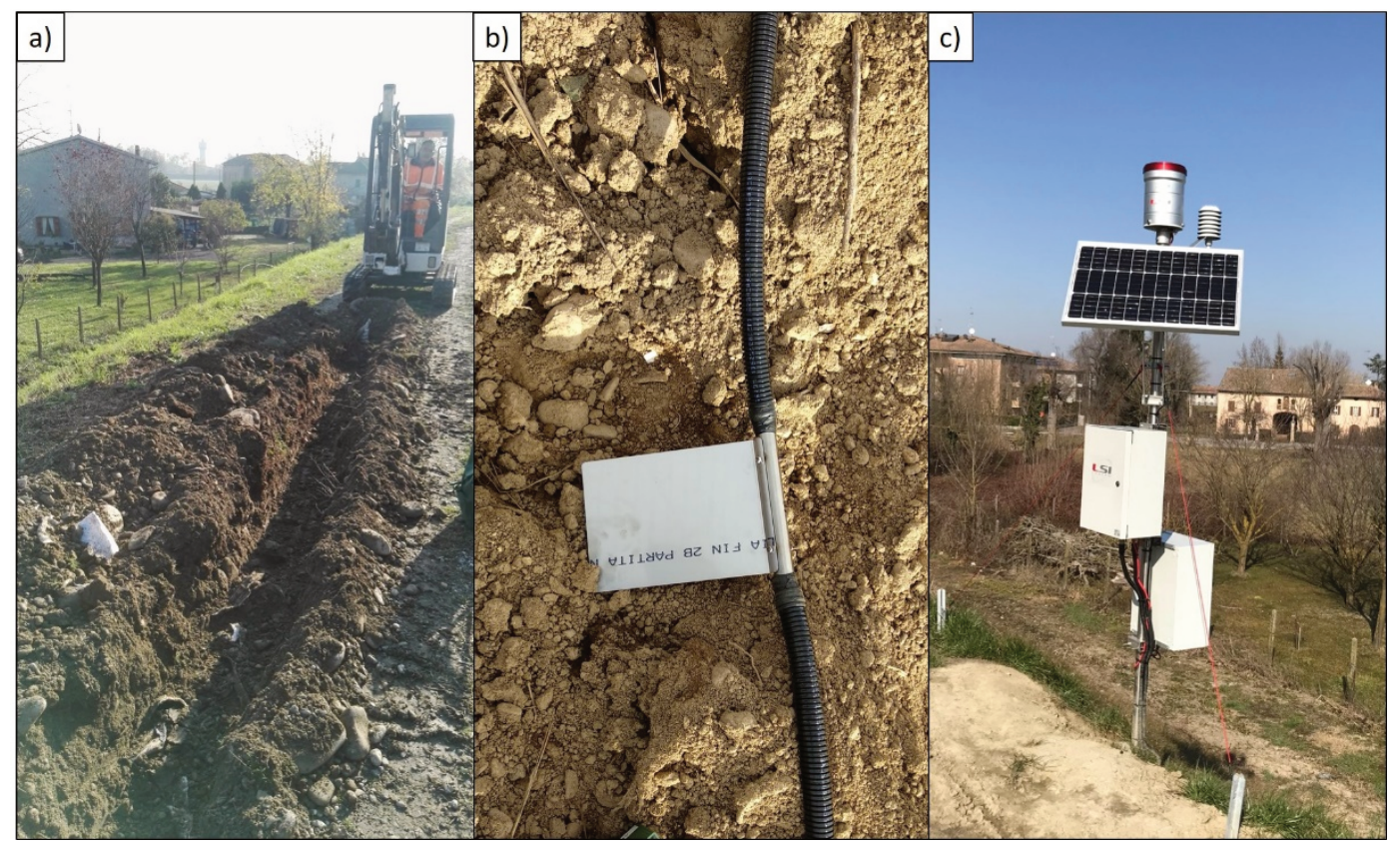

Figure 4 G.RE.T.A. installation in Colorno: (a) Trench on the top of the levee; (b) Protected cables and plate electrode; (c) Geo-resistivimeter and meteorological station boxes

A third monitoring system was installed in a pilot site near Santiago, Chile in late January 2020, the device is now in a testing phase, but the final destination for the installation will be a tailings dam in the country. In this case, the electrode spacing was increased to $3 \mathrm{~m}$, to have a lateral coverage of $141 \mathrm{~m}$ and a greater penetration depth, down to $22.5 \mathrm{~m}$. The two 24-channel cables and the 48 stainless steel plate electrodes were put in a $0.5 \mathrm{~m}$ deep trench and covered by soil (Figure 5 ).

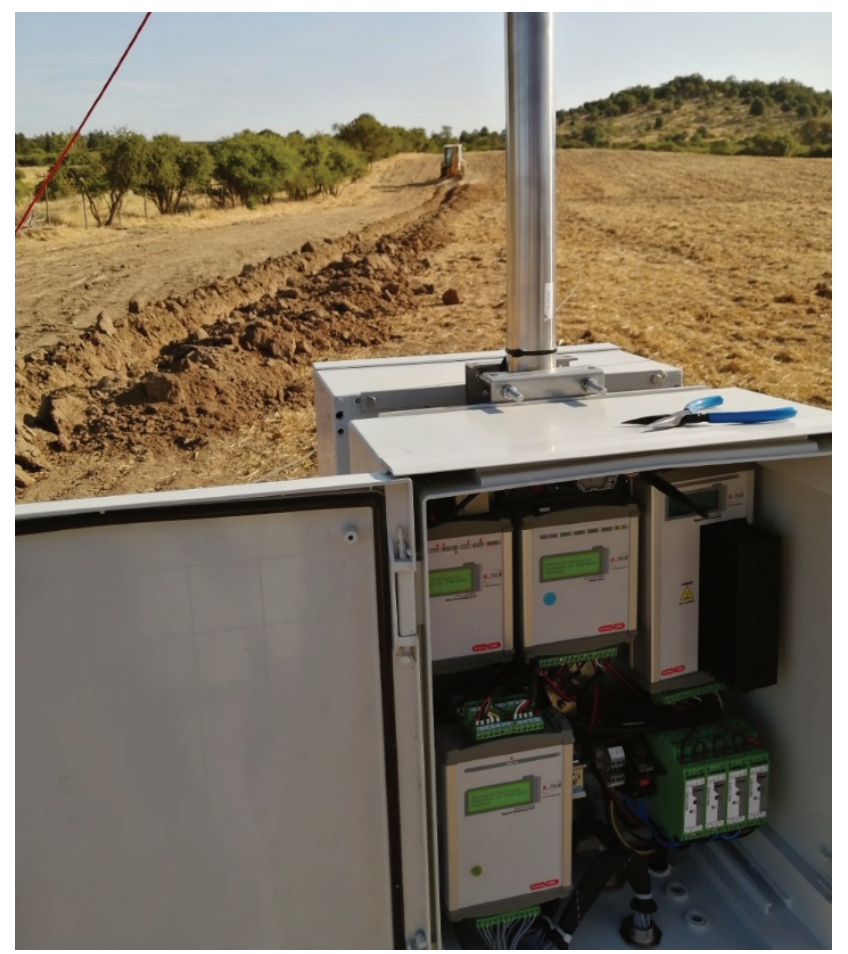

Figure 5 G.RE.T.A. installation in Chile: the measuring box (foreground) and the trench (background) 


\subsection{Laboratory tests on landslides}

Laboratory experiments were performed to test geo-electrical measurements as early warning systems for shallow rainfall-triggered landslides (Hojat et al. 2019c; Ivanov et al. ca. 2020). A landslide simulator was designed at the Applied Geology and Geophysical Laboratory of Politecnico di Milano, Lecco campus, with a base of $0.8 \times 2 \mathrm{~m}$ to be lifted through a hydraulic jack to a desired angle. Sprinklers were mounted on the frame of the structure to simulate artificial precipitations and GoPro cameras were installed to monitor the collapse process. The landslide body was simulated with a $15 \mathrm{~cm}$ thick mass of sand or combinations of sand, gravel and clay. To analyse the capability of ERT monitoring in detecting fractures and inhomogeneous infiltration, various tests were implemented with different values for slope angle, soil porosity and rainfall intensity. Every test was performed with a designed rainfall scheme (constant or increasing intensity, alternation of rainfall and pause of precipitation, etc.) until the collapse of the slope. For these small-scale studies, mini cables and electrodes were constructed and deployed in the centre of the slope along the maximum gradient line. Electrodes were covered with $1 \mathrm{~cm}$ of sand to prevent preferential flow paths in the landslide body. High-speed measurements, measuring one pseudosection every 3.5 minutes, were performed using 48 electrodes in Wenner configuration, with unit electrode spacing of $3 \mathrm{~cm}$. The basic idea is that high-frequency time-lapse geo-electrical measurements can monitor fast infiltration paths in the soil mass that are driven by different soil compactions and permeability. One initial measurement was also performed in each test providing useful information about the composition of the soil and the possible flow paths that would originate during rainfall. Since resistivity is also sensitive to the presence of fractures, weak zones were identified before collapse. This showed that real-time monitoring can thus be very helpful in identifying changes in soil properties due to water accumulation and fracturing, and can be used in an early warning procedure.

\section{$3 \quad$ Results}

\subsection{Field monitoring data}

The datasets from the two first sites, obtained after more than two years in San Giacomo delle Segnate and almost one year in Colorno, are processed and inverted every day. So far, a measurement per day is acquired in order to follow variations in soil properties due to changes in external variables. Data from the meteorological station are used to correlate variations in resistivity with temperature, rainfall, and variations of water level in the nearby river. Before analysing data recorded along a levee, it is important to consider the 3D effects of the levee structure on the 2D data (Arosio et al. 2018; Hojat et al. 2019d). 3D and 2D forward modellings are computed to analyse the influence of the geometry of the structure and of the variations in boundary conditions (presence of air or water on the downstream face of the embankment). Corrected data are then inverted and displayed in the dedicated website. The communication is very important when developing a device as part of an early warning system: through a client identity it is possible to log in to the database and not only program the device (e.g. frequency of measurements, measurement parameters, and type of measurement), but also to check the acquired data and make comparisons between different periods or days. Thresholds for changes in resistivity or water content can be set in order to send alarms to responsible users when the defined thresholds are exceeded.

No instability problems have emerged in either sites from the installation of the systems. However, the data have been used to study the influence of external variables on the resistivity values. The most important variables in San Giacomo delle Segnate, where the canal is used for irrigation, are the water level in the canal and the precipitation; while in Colorno, where the embankment is far from the river most of the year, rainfall is the predominant cause of variations in resistivity.

The display part of the website is shown in Figure 6: two different measurements in Colorno site have been selected and it is possible to calculate their difference. The apparent resistivity pseudosection shown at the top of Figure 5 was measured after a dry period (1 April 2019), while the one shown at the bottom was measured after a rainy period (1 June 2019). It is possible to see that the infiltration process is not 
homogenous in the levee segment; the renewed part (central part) is more clayey with a lower permeability, so the rainfall infiltrates more in older parts of the levee (lateral sides) resulting in resistivity decrease in these parts.

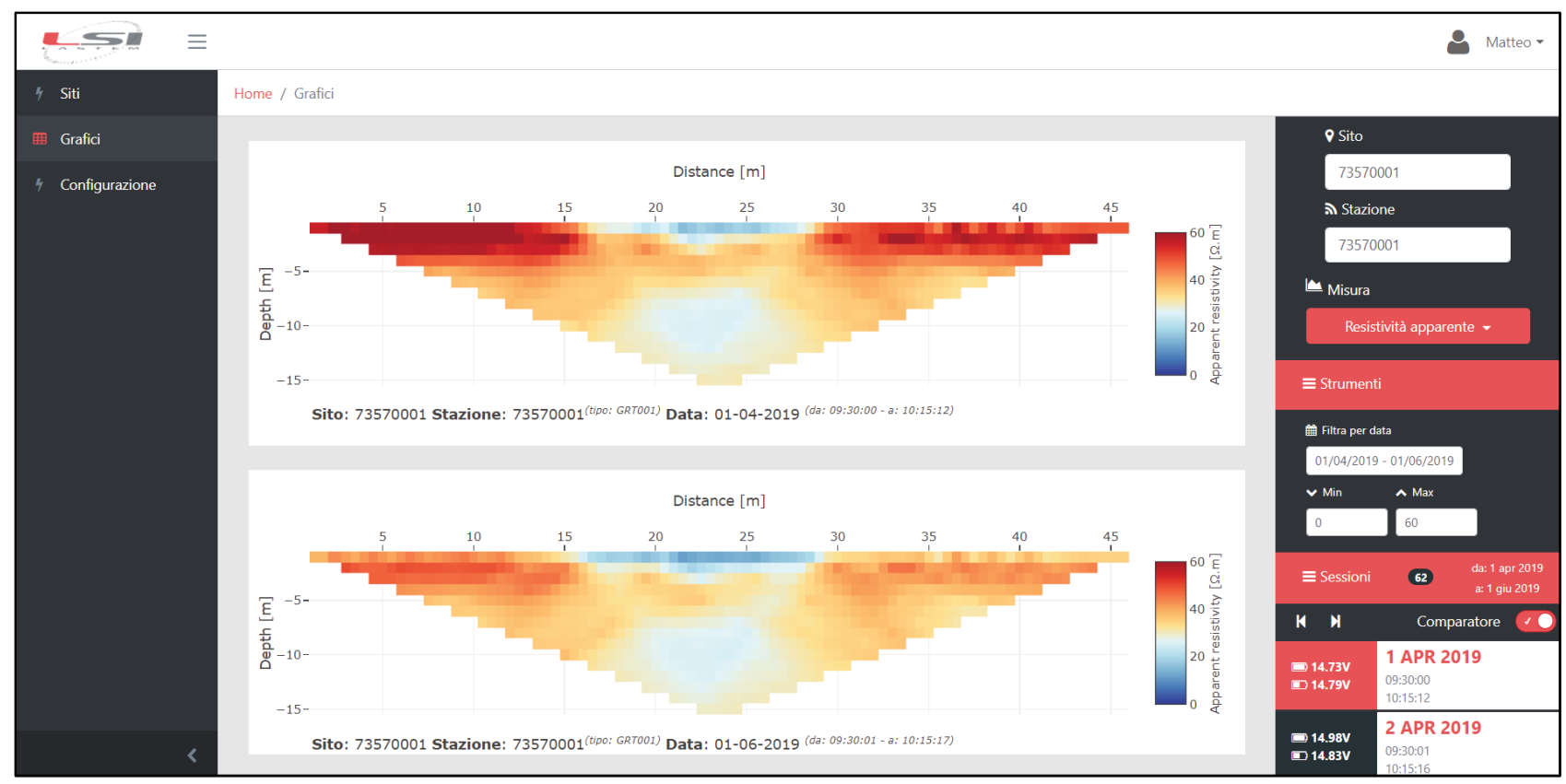

Figure 6 The general website of the G.RE.T.A. system, showing two examples of apparent resistivity pseudosections measured in Colorno on 1 April 2019 (top), 1 June 2019 (bottom)

\subsection{Laboratory data on landslide monitoring}

Time-lapse measurements of the downscaled landslides allow monitoring of how rainfall water infiltrates the soil during the presence or the pause of the simulated rainfall. For this purpose, the differences in the inverted resistivity sections can reveal the variations in resistivity principally due to the increasing or decreasing of water content. Using TDR data and Archie's law (Archie 1942) for sandy materials, or calibrating a curve between water content and resistivity through core samples data, resistivity maps can be converted to water saturation maps. It is thus possible to quantify the water saturation degree of the land mass-an important issue for stability analysis. What became evident from the laboratory tests on sandy material with slope inclinations of $33-40 \%$ made so far is that fractures appear on the border of non-homogeneous saturated zones and that water saturation exceeding $40-45 \%$ can be considered as an instability threshold.

Examples of percentage differences of inverted time-lapse ERT measurements are shown in Figure 7, indicating the percentage variation in terms of resistivity with respect to the preceding measurement. The test was performed alternating 10 minute rainy and dry periods until the collapse and ERT sections were recorded every 3.5 minutes. During rainfall, infiltration paths can be recognised and water moving from crown to toe (from right to left) is indicated by a decrease in resistivity values. After 7 minutes, the water content is increased in the entire soil body, and when rainfall stops, the desaturation process (described by increase of resistivity) takes place in the top part of the landslide, with water driven downward by gravity force. 


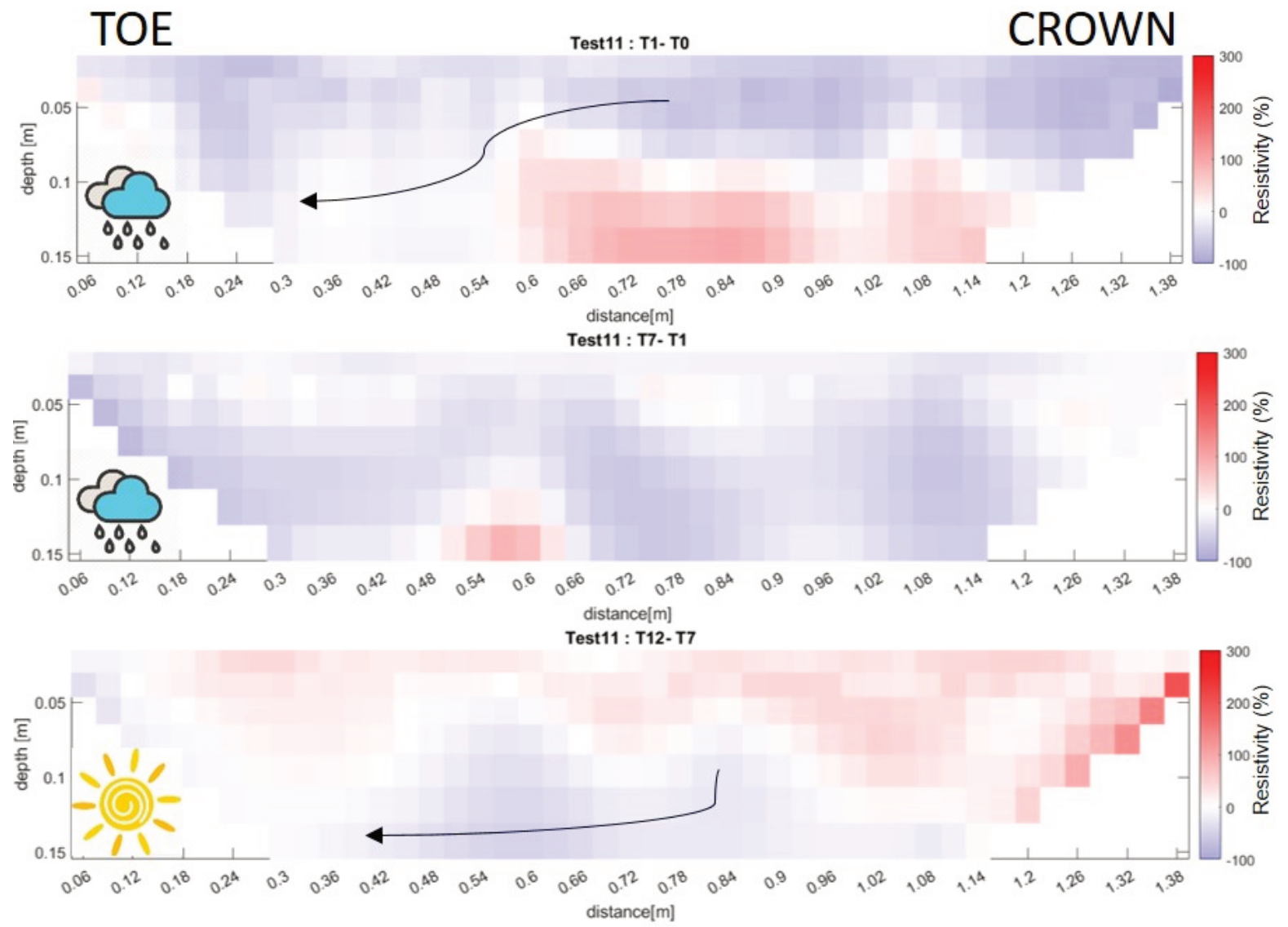

Figure 7 Time lapse percentage differences of inverted resistivity sections during one of the laboratory tests on the downscaled landslide. The presence or absence of rainfall is indicated by the cloud or the sun icons, respectively. Flow paths (arrows) can be recognised on images

Resistivity sections were also shown to be capable of detecting fractures prior to collapse, as shown in Figure 8. Comparing GoPro images with ERT inverted sections, it is possible to define fractures due to the very high resistivity values. What emerged was that sometimes ERT measurements could detect fractures before they were fully visible or recognisable by GoPro images. In most cases, GoPro photos and ERT sections simultaneously detected fractures, but the surface of the slope is flat and without vegetation in lab tests-a condition rarely found in real slopes. Therefore, ERT monitoring can be applied not only as a means to study water distribution in a landslide during rainfalls or after remediation, but can also be used as an early warning system to detect the formation of fractures which, due to vegetation, are not clearly visible from photogrammetry or satellite images. These tests have been addressed in landslide studies but can be easily applied to monitoring of any other geotechnical problem related to soil mass instability, fracturing problems, and inhomogeneous water distribution. 


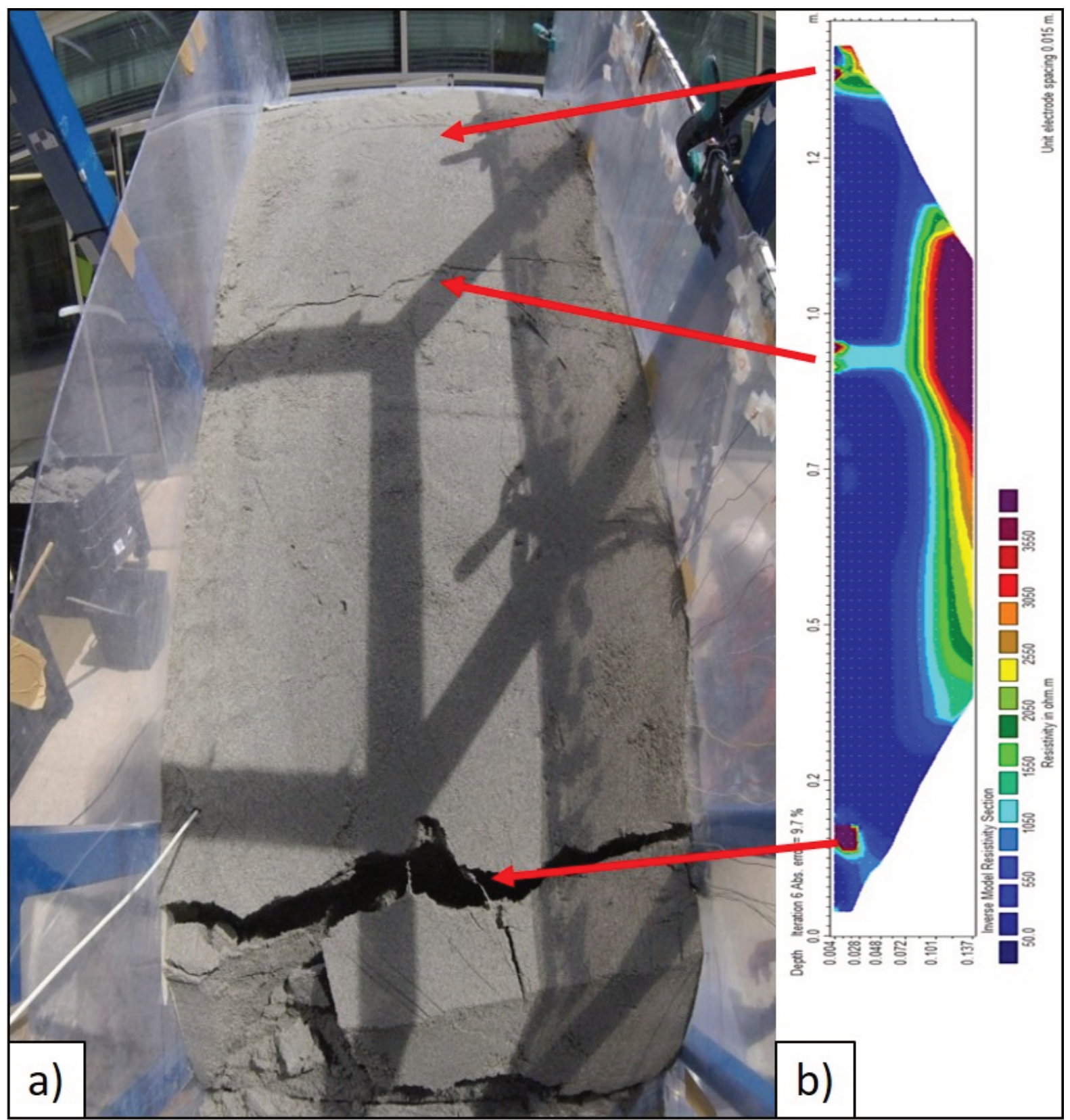

Figure 8 (a) One example of a GoPro image at a time when three fractures developed in the downscaled landslide; (b) The inverted resistivity section at the corresponding time to GoPro image: high resistivity values correspond to fractures that are also visible in the photo in this example

\section{Conclusions}

ERT measurements can be successfully used in different projects (hydrogeological risk assessment, landfill studies, tailings dams, etc.) to map heterogeneities in earth structures. In this study, embankments and landslides have been monitored through time-lapse geo-electrical measurements in order to recognise problems in earthen structures that can lead to instability. The technology proved to be sensitive to changes in water content, variations in soil properties and fracturing. Variations in geo-electrical behaviour of soil can be used as an indicator of instability and to trigger an alarm procedure. The geo-electrical monitoring system introduced in this paper, G.RE.T.A., has been tested and installed in three sites: a levee of an irrigation canal, the embankment of a river and a pilot site in Chile. The system works autonomously and can be programmed remotely. Data are sent through internet connection to a cloud-based database where they are inverted and processed to highlight changes. An alert procedure based on exceedance user-defined thresholds is 
implemented. In landslide laboratory tests, formation of fractures prior to collapse was recognised. Laboratory tests have underlined the possibility of recognising heterogeneities in landslide bodies that are predisposing factors to differential rainfall infiltration. Fractures originated in the landslide body can be mapped prior to collapse thanks to the sensitivity of the resistivity to the presence of air in the structures. This provides a useful tool to mitigate hydrogeological risks and to prevent environmental problems, thanks to the real-time monitoring of the inner condition of earthen structures and the alert system based on changes in soil properties. Monitoring in pilot sites so far has permitted the assessment of heterogeneous rainfall infiltration with time and seepage paths in levee structures while boundary conditions change.

ERT measurements are well known in the mining sector, but mainly as one-shot measurements for mineral exploration, groundwater studies and assessing subsurface structures. Some studies may employ time-lapse measurements, but with frequencies of months or years. The novel approach of monitoring described in this paper can be implemented as an efficient breakthrough to map heterogeneities that are successfully underlined by differences in resistivity values. The system can be used as an early warning system for sudden changes in inner properties of piles or tailings dams, to assess the flow paths of acid mining drainage or to evaluate the efficacy of a heap leaching operation.

\section{Acknowledgement}

The research was partially funded by Ministero dell'Ambiente e della Tutela del Territorio e del Mare (DG SUA), grant DILEMMA. The authors thank Consorzio di Bonifica Terre dei Gonzaga in Destra Po, Consorzio di Bonifica Est Ticino Villoresi, and Agenzia Interregionale Per II Fiume Po for their collaboration. The monitoring system has been developed with the scientific contribution of Politecnico di Milano and technical support of LSI Lastem.

\section{References}

Archie, GE 1942, 'The electrical resistivity log as an aid in determining some reservoir characteristics', Petroleum Transactions of the AIME, vol. 146, pp. 54-62

Arosio, D, Munda, S, Tresoldi, G, Papini, M, Longoni, L \& Zanzi, L 2017, 'A customized resistivity system for monitoring saturation and seepage in earthen levees: installation and validation', Open Geosciences, vol. 9, pp. 457-467.

Arosio, D, Hojat, A, Ivanov, VI, Loke, MH, Longoni, L, Papini, M, ... \& Zanzi, L 2018, 'A laboratory experience to assess the 3D effects on 2D ERT monitoring of river levees', Proceeding of Near Surface Geoscience 2018, European Association of Geoscientists \& Engineers, Houten, We 24A 05, https://doi.org/10.3997/2214-4609.201802628

Borgatti, L, Forte, E, Mocnik, A, Zambrini, R, Cervia, F, Martinucci, D, Pellegrini, F, Pillon, S, Prizzon, A \& Zamariolo, A 2017, 'Detection and characterization of animal burrows within river embankments by means of coupled remote sensing and geophysical techniques: lessons from River Panaro (northern Italy)', Engineering Geology, vol. 226, pp. 277-289.

Busato, L, Boaga, J, Peruzzo, L, Himi, M, Cola, S, Bersan, S \& Cassiani, G 2016, 'Combined geophysical surveys for the characterization of a reconstructed river embankment', Engineering Geology, vol. 211, pp. 74-84.

Cardarelli, E, Cercato, M \& Di Filippo, G 2010, 'Geophysical investigation for the rehabilitation of a flood control embankment', Near Surface Geophysics, vol. 8, no. 4, pp. 287-296.

Cardarelli, E, Cercato, M, De Donno, G 2014, 'Characterization of an earth-filled dam through the combined use of electrical resistivity tomography, P-and SH-wave seismic tomography and surface wave data', Journal of Applied Geophysics, vol. 106, pp. 87-95.

Camarero, PL, Moreira, CA \& Pereira, HG 2019, 'Analysis of the physical integrity of earth dams from electrical resistivity tomography (ERT) in Brazil', Pure of Applied Geophysics, pp.1-13, https://doi.org/10.1007/s00024-019-02271-8

Chambers, JE, Gunn, DA, Wilkinson, PB, Meldrum, PI, Haslam, E, Holyoake, S, ... \& Wragg, J 2014, '4D electrical resistivity tomography monitoring of soil moisture dynamics in an operational railway embankment', Near Surface Geophysics, no 12, pp. 61-72.

Crawford, MM \& Bryson, LS 2018, 'Assessment of active landslides using field electrical measurements', Engineering Geology, vol. 233, pp. 146-159.

Di Prinzio, M, Bittelli, M, Castellarin, A \& Rossi Pisa, P 2010, 'Application of GPR to the monitoring of river embankments', Journal of Applied Geophysics, vol. 71, pp. 53-61.

Dimech, A, Chouteau, M, Aubertin, M, Bussière, B, Martin, V \& Plante, B 2019, 'Three-dimensional time-lapse geoelectrical monitoring of water infiltration in an experimental mine waste rock pile', Vadose Zone Journal, vol. 18, no. 1 , https://doi.org/10.2136/vzj2018.05.0098

Francese, R \& Monteiro Santos, F 2014, 'Towards a global approach to scan earthen levees', Proceedings of SEG Meeting, Society of Exploration Geophysicists, Tulsa.

Gunn, DA, Chambers, JE, Dashwood, BE, Lacinska, A, Dijkstra, T, Uhlemann, S, ... \& Donohue, S 2018, 'Deterioration model and condition monitoring of aged railway embankment using non-invasive geophysics', Construction and Building Materials, vol. 170, pp. 668-678. 
Hibert, C, Grandjean, G, Bitri, A, Travelletti, J \& Malet, JP 2012, 'Characterizing landslides through geophysical data fusion: example of the La Valette landslide (France)', Engineering Geology, vol. 128, pp. 23-29.

Hojat A, Arosio D, Di Luch I, Ferrario M, Ivov Ivanov V, Longoni L, ... \& Zanzi L 2019a, 'Testing ERT and fiber optic techniques at the laboratory scale to monitor river levees', Proceedings of the 25th European Meeting of Environmental and Engineering Geophysics, European Association of Geoscientists \& Engineers, Houten, https://doi.org/10.3997/2214-4609.201902440

Hojat, A, Arosio, D, Longoni, L, Papini, M, Tresoldi, G \& Zanzi, L, 2019b, 'Installation and validation of a customized resistivity system for permanent monitoring of a river embankment', Proceedings of EAGE-GSM 2nd Asia Pacific Meeting on near Surface Geoscience \& Engineering, European Association of Geoscientists \& Engineers, Houten, https://doi.org/10.3997/22144609.201900421

Hojat, A, Arosio, D, Ivanov, VI, Longoni, L, Papini, M, Scaioni, M, ... \& Zanzi, L 2019c, 'Geoelectrical characterization and monitoring of slopes on a rainfall-triggered landslide simulator', Journal of Applied Geophysics, vol. 107, no. 103844, https://doi.org/10.1016/j.jappgeo.2019.103844

Hojat, A, Arosio, D, Loke, MH, Longoni, L, Papini, M, Tresoldi, G \& Zanzi, L 2019d, 'Assessment of 3D geometry effects on 2D ERT data of a permanent monitoring system along a river embankment', Proceedings of EAGE-GSM 2nd Asia Pacific Meeting on Near Surface Geoscience \& Engineering, European Association of Geoscientists \& Engineers, Houten, https://doi.org/10.3997/2214-4609.201900427

Huntley, D, Bobrowsky, P, Hendry, M, Macciotta, R, Elwood, D, Sattler, ... \& Meldrum, P 2019, 'Application of multi-dimensional electrical resistivity tomography datasets to investigate a very slow-moving landslide near Ashcroft, British Columbia, Canada', Landslides, vol. 16, no. 5, pp. 1033-1042, https://doi.org/10.1007/s10346-019-01147-1

Hudson, E, Kulessa, B, Edwards, P, William, T \& Walsh, R 2018, 'Integrated hydrological and geophysical characterisation of surface and subsurface water contamination at abandoned metal mines', Water Air Soil Pollution, vol. 229, p. 256, https://doi.org/10.1007/s11270-018-3880-4

Inazaki, T, Kaneko, M \& Aoike, K 2016, 'Detailed geophysical imaging of the shallow surfaces at an underseepage site behind of a levee', Proceedings of the Symposium on the Application of Geophysics to Engineering and Environmental Problems, Environmental \& Engineering Geophysical Society, Houten, https://doi.org/10.4133/SAGEEP.29-020

Ivanov, VI, Tresoldi, G, Arosio, D, Hojat, A, Zanzi, L, Papini, M \& Longoni, L ca. 2020, 'Evaluation of the effect of wetting front propagation on the stability of shallow land masses at the laboratory scale', Water (under review).

Jomard, H, Lebourg, T, Guglielmi, Y \& Tric, E 2010, 'Electrical imaging of sliding geometry and fluids associated with a deep seated landslide (La Clapière, France)', Earth Surface Processes and Landforms, vol. 35, no. 5, pp. 588-599, https://doi.org/10.1002/esp.1941

Jodry, C, Sérgio, PL, Fargier, Y, Sanchez, M \& Côte, P 2019, '2D-ERT monitoring of soil moisture seasonal behaviour in a river levee: a case study', Journal of Applied Geophysics, vol. 167, pp. 140-151, https://doi.org/10.1016/j.jappgeo.2019.05.008

Karimi Nasab, S, Hojat, A, Kamkar-Rouhani, A, Akbari Javar, H \& Maknooni, S 2011, 'Successful use of geoelectrical surveys in Area 3 of the Gol-e-Gohar iron ore mine, Iran', Mine Water and the Environment, vol. 30, no. 208, https://doi.org/10.1007/s10230011-0135-7

Kotikian, M, Parsekian, AD, Paige, G \& Carey, A 2019, 'Observing heterogeneous unsaturated flow at the hillslope scale using time-lapse electrical resistivity tomography', Vadose Zone Journal, vol. 18, no. 180138, https://doi.org/10.2136/vzj2018.07.0138

Martín-Crespo, T, Gómez-Ortiz, D, Martín-Velázquez, S, Lillo, J \& Faz, A 2019, 'Geoenvironmental characterization of sulfide mine tailings', in Intechopen (eds), Geochemistry, https://doi.org/10.5772/intechopen.84795

Moradipour, M, Ranjbar, H, Hojat, A, Karimi Nasab, S \& Daneshpajouh, S 2016, 'Laboratory and field measurements of electrical resistivity to study heap leaching pad no. 3 at Sarcheshmeh copper mine', Proceedings of Near Surface Geoscience 2016, European Association of Geoscientists \& Engineers, Houten, https://doi.org/10.3997/2214-4609.201602140

Morelli, G \& Francese, R 2013, 'A fast and integrated geophysical imaging system for large scale levee monitoring', Proceedings of the Symposium on the Application of Geophysics to Engineering and Environmental Problems, Environmental \& Engineering Geophysical Society, Houten.

Perri, MT, Boaga, J, Bersan, S, Cassiani, G, Cola, S, Deiana, R, Simonini, P \& Patti, S 2014, 'River embankment characterization: the joint use of geophysical and geotechnical techniques', Journal of Applied Geophysics, vol. 110, pp. 5-22.

Piegari, E, Cataudella, V, Di Maio, R, Milano, L, Nicodemi, M \& Soldovieri, MG 2008, 'Electrical resistivity tomography and statistical analysis in landslide modelling: a conceptual approach', Journal of Applied Geophysics, vol. 68, no. 2, pp. 151-158.

Rucker, DF, Schindler, A, Levitt, MT \& Glaser, DR 2009, 'Three-dimensional electrical resistivity imaging of a gold heap', Hydrometallurgy, vol. 98, pp. 267-275, https://doi.org/10.1016/j.hydromet.2009.05.011

Schenato, L, Palmieri, L, Camporese, M, Bersan, S, Cola, S, Pasuto, A, ... \& Simonini, P 2017, 'Distributed optical fibre sensing for early detection of shallow landslides triggering', Scientific Reports 7, no. 14686, https://doi.org/10.1038/s41598-017-12610-1

Sjödahl, P, Dahlin, T, Johansson, S \& Loke, MH 2008, 'Resistivity monitoring for leakage and internal erosion detection at Hällby embankment dam', Journal of Applied Geophysics, vol. 65, no. 3-4, pp. 155-164.

Supper, R, Ottowitz, D, Jochum, B, Kim, JH, Römer, A, Baron, I, ... \& Vecchiotti, F 2014, 'Geoelectrical monitoring: an innovative method to supplement landslide surveillance and early warning', Near Surface Geophysics, vol. 12, pp. 133-150.

Tresoldi, G, Arosio, D, Hojat, A, Longoni, L, Papini, M \& Zanzi, L 2018, 'Tech-Levee-Watch: experimenting an integrated geophysical system for stability assessment of levees', Rendiconti Online Societa Geologica Italiana, vol. 46, pp. 38-43, https://doi.org/10.3301/ROL.2018.49

Tresoldi, G, Arosio, D, Hojat, A, Longoni, L, Papini, M \& Zanzi, L 2019, 'Long-term hydrogeophysical monitoring of the internal conditions of river levees', Engineering Geology, vol. 259, no. 105139, https://doi.org/10.1016/j.enggeo.2019.05.016 